\title{
Crescimento de girassol como flor em vaso em função de doses de paclobutrazol
}

\author{
Christina da Silva Wanderley ${ }^{1}$, Ricardo Tadeu de Faria ${ }^{2}$, Roberto Rezende ${ }^{3}$
}

\section{RESUMO}

O girassol (Helianthus annuus L.), que é comumente cultivado para produção de sementes e óleo, também apresenta potencial de uso como planta ornamental. Entretanto, seu porte elevado dificulta essa utilização, principalmente como flor em vaso. Objetivou-se neste experimento avaliar os efeitos do regulador de crescimento paclobutrazol sobre o crescimento de plantas de girassol em vaso, cultivadas em sistema hidropônico, dentro de estufa, em vasos preenchidos com sílica moída. Os dois genótipos de girassol utilizados foram BRS Oásis, com capítulo marrom e altura média de 1,85 m, e Helio 358, com capítulo amarelo e altura média de 1,45 m. As doses de paclobutrazol avaliadas foram $0 ; 0,5 ; 1 ; 2 ; 4 ;$ e $6 \mathrm{mg} \mathrm{L}^{-1}$, aplicadas diretamente no substrato de sílica moída. A solução nutritiva utilizada foi a de Hoagland, e as plantas foram mantidas sob aeração constante. O delineamento experimental foi o de blocos casualizados, em esquema fatorial com cinco repetições, totalizando 60 parcelas. Avaliaram-se a altura das plantas e a massa de matéria seca de raiz, caule, folhas e de capítulos. Houve efeito do paclobutrazol sobre o crescimento das plantas. O uso do paclobutrazol na dose de $2 \mathrm{mgL}^{-1}$ reduz a altura do girassol, porém não afeta a qualidade da inflorescência, o que pode viabilizar o seu uso na produção de flores de girassol como ornamentais. A sensibilidade ao paclobutrazol é maior para o genótipo Helio 358 em relação ao genótipo BRS Oásis.

Palavras-chave: reguladores, altura de planta, Helianthus annuus L.

\section{ABSTRACT}

\section{Growth of potted sunflower in response to paclobutrazol}

Sunflower, besides being an oil seed crop, is also grown as an ornamental plant. However, its great growth in height makes such use difficult, especially as pot flower. This study aimed to evaluate the effects of the growth regulator paclobutrazol on the growth of potted sunflowers in a hydroponic system, in pots filled with milled silica in a greenhouse. Two sunflower genotypes BRS Oásis with brown head and average height of 1,85 $\mathrm{m}$ and Helio 358, with yellow head and average height of $1,45 \mathrm{~m}$. The rates of paclobutrazol evaluated were $0 ; 0.5 ; 1 ; 2 ; 4$ and $6 \mathrm{mg} \mathrm{L}^{-1}$, directly applied on the milled silica substrate. The plants were maintained in Hoagland nutrient solution under constant aeration. The experiment was arranged in a factorial complete randomized block, design with five repetitions, totaling 60 plots. The variables evaluated were plant height, dry phytomass of root, stem, leaves and heads. There was no effect of paclobutrazol on plant growth. Paclobutrazol reduced the height of cultivars Helio 358 and BRS Oásis at all rates. Rates higher than $2 \mathrm{mg} \mathrm{L}^{-1}$ and $4 \mathrm{mg} \mathrm{L}^{-1}$ reduced the growth of the genotypes BRS Oásis and Helio 358 respectively. Sensitivity to paclobutrazol is greater for the genotype Helio 358 than forBRS Oásis.

Key words: growth regulators, plant height, Helianthus annuus L.

Recebido para publicação em 24/06/2011 e aprovado em 11/07/2013.

'Engenheira-Agrônoma, Doutora. Departamento de Agronomia, Universidade Estadual de Londrina, Rua Professor João Cândido, 818, apto 301, 86010-000, Londrina, Paraná, Brasil. chriscsw@sercomtel.com.br (autora para correspondência).

${ }^{2}$ Engenheiro-Agrônomo, Ph.D. Departamento de Agronomia, Universidade Estadual de Londrina, Rua Deputado Fernando Ferrari, 141, 86062-030, Londrina, Paraná, Brasil. faria@uel.br

${ }^{3}$ Engenheiro-Agrônomo, Doutor. Departamento de Agronomia, Universidade Estadual de Maringá, Avenida Colombo, 5790, Bloco 32, Sala 07, 87020-900, Maringá, Paraná, Brasil. rrezende@uem.br 


\section{INTRODUÇÃO}

O girassol ornamental é uma planta bastante apreciada como flor de vaso devido à variação de cores e exuberância da inflorescência. Comercialmente, apresenta a vantagem do ciclo curto, cerca de 50 dias, e de facilidade de propagação por sementes. Por outro lado, a planta possui porte elevado, o que dificulta o uso ornamental. Segundo Reyes et al. (1985), o girassol, dependendo do genótipo, pode atingir de 1,60 até 3,0 m de altura. Esse porte tem se mostrado problemático para produção e comercialização dessa espécie quando usada para ornamentação, pois para flores em vaso buscam-se plantas com arquitetura diferenciada e altura média de $35 \mathrm{~cm}$.

Uma estratégia rápida para controlar o porte em plantas é o uso de fitorreguladores. Geralmente são produtos sintéticos que inibem a síntese de giberelinas, como o chlormequat, paclobutrazol e uniconazole, os quais vêm sendo utilizados em plantas ornamentais para o controle de vigor e altura. Comparando-se o efeito do daminozide, chlormequat e paclobutrazol em arbustos ornamentais, Joustra (1989) não obteve diferenças entre as respostas de vigor. Vernieri et al. (2003) compararam paclobutrazol e flurprimidol aplicados em girassóis cultivados em vasos e obtiveram para redução de altura de plantas as melhores respostas quando se aplicou paclobutrazol. Esse produto tem sido muito utilizado como regulador de crescimento em diversas espécies de plantas, e pode se apresentar mais efetivo quando aplicado diretamente no substrato, em concentrações que podem variar de 2 a $90 \mathrm{mg} \mathrm{L}^{-1}$ (Barret, 2001).

Para que as plantas possam se desenvolver adequadamente, permitindo produção de flores em quantidade e com qualidade, é necessário que se forneçam suporte adequado e nutrição equilibrada. Uma das alternativas é o uso do cultivo em sistema hidropônico, onde se aplica a solução nutritiva balanceada e reduz o risco de subdesenvolvimento por limitação de água e nutrientes minerais (Bliska Junior \& Honório, 1996). Diversas soluções nutritivas vêm sendo empregadas no cultivo de plantas. A solução proposta Hoagland, modificada por Epstein \& Bloom (2004), é uma das mais utilizadas por se adequar ao cultivo de várias espécies.

Assim, objetivou-se neste trabalho avaliar os efeitos do regulador de crescimento paclobutrazol em dois genótipos de girassol, cultivados em sistema hidropônico.

\section{MATERIAL E MÉTODOS}

O experimento foi realizado no período de dezembro de 2007 a abril de 2008, em casa de vegetação, na Embrapa Soja, na cidade de Londrina, Paraná. Os genótipos utilizados foram BRS Oásis, desenvolvido pela Embrapa Soja, com capítulo marrom e altura média de 1,85 m, e Helio 358, desenvolvido pela empresa Helianthus do Brasil, com capítulo amarelo e altura média de $1,45 \mathrm{~m}$. O cultivo das plantas foi realizado em sistema hidropônico, em vasos com substrato inerte de sílica, onde se aplicou a solução nutritiva e aeração permanente através de compressor de ar. Foram utilizados vasos brancos, com capacidade para 3,6 litros, contendo 4,3 kg de sílica moída e 1,4 L da solução nutritiva de Hoagland, modificada por Epstein \& Bloom (2004). Foi utilizado o delineamento experimental de blocos casualizados em fatorial de 2 x 6 (genótipos $\mathrm{x}$ concentração de paclobutrazol), com cinco repetições com parcela composta por uma planta.

As concentrações de paclobutrazol foram $0 ; 0,5 ; 1 ; 2$; 4; e $6 \mathrm{mg} \mathrm{L}^{-1}$, conforme experimentos realizados por Wanderley et al. (2007).

As sementes foram previamente germinadas em bandejas de isopor preenchidas com areia e umedecidas somente com água destilada. Quatro dias após a emergência, as mudas foram transplantadas para os vasos com sílica, mantendo-se uma planta por vaso. As plantas permaneceram em solução nutritiva diluída a $25 \%$ e $50 \%$, respectivamente do $4^{\circ}$ ao $6^{\circ}$ e do $7^{\circ}$ ao $9^{\circ}$ dias após o transplante. Dez dias após o transplantio, iniciaram-se os tratamentos pela aplicação de paclobutrazol diretamente nos vasos, através de pipeta volumétrica nas concentrações previamente definidas e pela substituição da solução nutritiva diluída por solução completa. Os vasos receberam complementação de água diariamente, mantendo-se o volume constante, e a cada 15 dias trocava-se a solução nutritiva.

O crescimento vegetativo dos dois genótipos foi avaliado pela altura da planta, a cada 20 dias após a emergência, e a avaliação final da altura foi realizada no florescimento, medida com o auxílio de trena, a partir da inserção dos cotilédones até a parte inferior do capítulo e das fitomassas das matérias secas de raízes, caules, folhas e capítulos.

Os dados obtidos foram submetidos à análise de variância, adotando-se 5\% de probabilidade de erro, quando significativos ao teste de regressão para o fator quantitativo, utilizando-se o programa SAS.

\section{RESULTADOS E DISCUSSÃO}

Para a altura das plantas no florescimento, a aplicação de paclobutrazol proporcionou redução do crescimento tanto para BRS Oásis quanto para Helio 358 (Figura 1).

Essa redução foi relacionada com os níveis do regulador de crescimento usado, fato também verificado por Barbosa et al. (2009), os quais obtiveram efeito linear decrescente para a altura de plantas de girassol com o aumento da concentração de paclobutrazol.

Os efeitos verificados no presente trabalho foram mais expressivos sobre o genótipo Helio 358, visto que este 
apresentou, mesmo na ausência do tratamento, menor altura final (redução de $90 \%$ na altura com a maior dose de paclobutrazol, comparado a testemunha), enquanto para BRS Oásis houve redução de $78 \%$ em altura, demonstrando haver influência genética sobre os resultados, fato também constatado por Whipker \& MC Call (2000) e Pallez et al. (2002), que também obtiveram respostas quando estudaram diferentes genótipos de girassol. Segundo Dasoju et al.(1998), plantas de girassol mostraram maior redução da altura de acordo com o aumentou da concentração de paclobutrazol, fato que também foi verificado no presente trabalho. Incrocci et al. (2003) concluíram que o tratamento com o regulador de crescimento não somente reduziu a altura das plantas como também aumentou a sua uniformidade. Esse fato corrobora as informações de Vernieri et al. (2003), os quais atestaram que, além de ter ocorrido aumento na uniformidade das plantas, não houve efeito negativo na sua qualidade. Ribeiro et al. (2007) também verificaram efeitos significativos na redução na altura de plantas de girassol tratadas com paclobutrazol. Para todas as concentrações foi verificada diferença estatística na altura entre os genótipos e também entre todas elas em comparação com a testemunha.

Para a variável massa da matéria seca de raiz, houve indicação de que a resposta dos genótipos ao regulador é variável com a dose do produto aplicado (Figura 2). Segundo Wilkinson \& Richards (1987), estudos relatam que a aplicação de paclobutrazol via substrato, em concentrações elevadas, pode reduzir severamente o crescimento do sistema radicular. Para o genótipo Helio 358, verificouse que doses crescentes de paclobutrazol reduziram significativamente a quantidade de massa seca de raiz, enquanto para BRS Oásis, nos tratamentos 0,5 e $1 \mathrm{mg} \mathrm{L}^{-1}$ e para as plantas testemunha não houve essa redução, que só foi verificada a partir da dose $2 \mathrm{mg} \mathrm{L}^{-1}$ e superiores. De toda maneira, para todas as doses os maiores valores de massa seca de raízes foram encontrados para BRS Oásis. Para a variedade BRS Oásis, houve aumento de 20,9\% na massa seca de raízes na dose de $2 \mathrm{mg} \mathrm{L}^{-1}$, enquanto na Helio 358 ocorreu redução de $76 \%$ nessa mesma dose, quando comparada ao controle. Segundo Gianfagna (1988), esse produto tem pouco efeito em crescimento de raízes, mas os resultados obtidos no presente trabalho revelam tendência diferente, já que para Helio 358 houve redução da fitomassa seca de raízes conforme aumentaram as doses de paclobutrazol, e para BRS Oásis houve aumento até a dose de $2 \mathrm{mg} \mathrm{L}^{-1}$ e depois redução drástica dos valores de fitomassa seca das raízes. Isso leva a inferir que esses efeitos sejam devidos às variações genéticas desses dois materiais. Valle \& Almeida (1991) encontraram reduções de fitomassas secas de raízes de plântulas de cacau com a aplicação de paclobutrazol, concordando com os resultados encontrados no presente trabalho.

As doses de paclobutrazol influenciaram os valores de massa da matéria seca do caule (Figura 3). Não foram observadas diferenças estatísticas entre os genótipos para as plantas testemunha e para as que receberam aplicação das doses 4 e $6 \mathrm{mg} \mathrm{L}^{-1}$. Para as plantas que receberam as doses 0,$5 ; 1$; e $2 \mathrm{mg} \mathrm{L}^{-1}$, as diferenças foram significativas. Houve comportamento semelhante dos dois genótipos para todas as doses, com reduções da massa seca do caule conforme se aumentaram as doses de paclobutrazol. Em todos os tratamentos, o genótipo Helio 358 apresentou menores valores de massa seca, inclusive para a testemunha. Essas diferenças, em princípio, devem-se à constituição genética, já que BRS Oásis, apesar de ser ornamental, não apresentou modificações em altura e pode atingir quase dois metros, diferenciando-se dos outros genótipos pela cor e pelo tamanho de capítulo. O Helio 358 apresenta altura média de plantas a campo entre 1,55 e 1,75 m (Embrapa, 2004). Com a aplicação de paclobutrazol, o efeito de redução de alongamento do caule e a redução de massa seca foram mais pronunciados em Helio 358.

Esse comportamento de redução de massa seca de caule poderia ser considerado como esperado, já que o paclobutrazol é um regulador de crescimento, cuja ação é

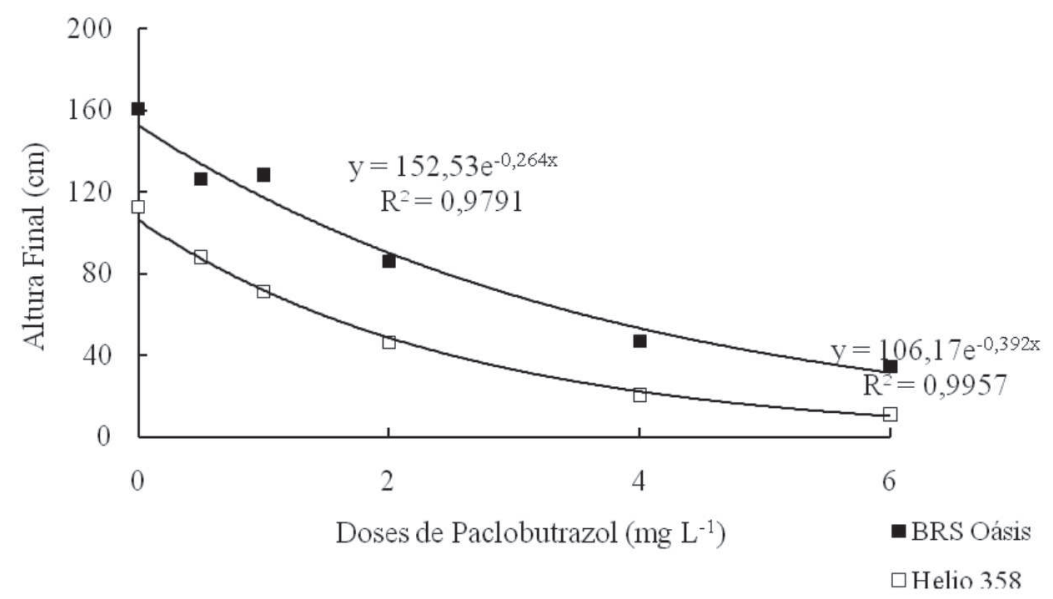

Figura 1. Altura de plantas de girassol dos genótipos BRS Oásis e Helio 358 em razão de doses de paclobutrazol. 
reduzir o alongamento do caule (Almeida \& Pereira, 1996). Entretanto, a aplicação de paclobutrazol, além de reduzir a altura do caule, pode causar seu engrossamento, nem sempre reduzindo a sua massa seca. Segundo Mauk et al. (1990), o paclobutrazol aplicado ao solo inibe o crescimento do caule em girassol, podendo causar nanismo. Resultados semelhantes aos encontrados neste trabalho foram relatados por Valle \& Almeida (1991), em estudos realizados com cacau, e por Ribeiro et al. (2007), em trabalho com girassol, ambos utilizando o paclobutrazol como regulador de crescimento. Pateli et al. (2004) observaram que o aumento de doses de paclobutrazol reduziram progressivamente o comprimento da haste principal em Epidendrum radicans. Esses resultados sugerem que o efeito do paclobutrazol como inibidor de síntese de giberelina atua no nível de células, seja em células de folhas, produção de matéria seca, elongação de caules ou outras características (Stefanini et al., 2002).

Para a fitomassa da matéria seca de folhas, os genótipos apresentaram comportamento diferente em relação às doses de paclobutrazol (Figura 4). Para o BRS Oásis, o aumento das concentrações até $1 \mathrm{mg} \mathrm{L}^{-1}$ proporcionou aumento da fitomassa seca das folhas, e a partir de $2 \mathrm{mg}$ $\mathrm{L}^{-1}$ houve redução na massa seca das folhas. Para o He- lio 358, também houve redução nas massas secas de folhas a partir da dose de $1 \mathrm{mg} \mathrm{L}^{-1}$ Assim como para as raízes, verificou-se efeito positivo do paclobutrazol nas menores doses sobre o genótipo BRS Oásis. Valle \& Almeida (1991) também encontraram redução de fitomassas secas de folhas com a aplicação de paclobutrazol em plântulas de cacau. Pateli et al. (2004) verificaram que reguladores de crescimento têm efeito sobre o tamanho de folhas de Epidendrum radicans e que elas foram muito reduzidas em todas as doses de paclobutrazol que foram aplicadas. Da mesma forma, Pinto et al. (2006) constataram que houve relação linear significativa entre o aumento de concentração de paclobutrazol e o comprimento da bainha foliar. Verificaram também que a porcentagem de massa seca de bainha foliar foi significativamente menor em plantas tratadas com paclobutrazol, comparado com as plantas controle. De acordo com Pinto et al. (2006), a inibição na síntese de giberelinas pelos reguladores de crescimento reduz o alongamento dos tecidos primários e a expansão foliar, promovendo ou não afetando a expansão e divisão celular transversal. A iniciação foliar pode não ser inibida na mesma intensidade que o alongamento quando os reguladores reduzem a atividade do meristema subapical, sem romper a função

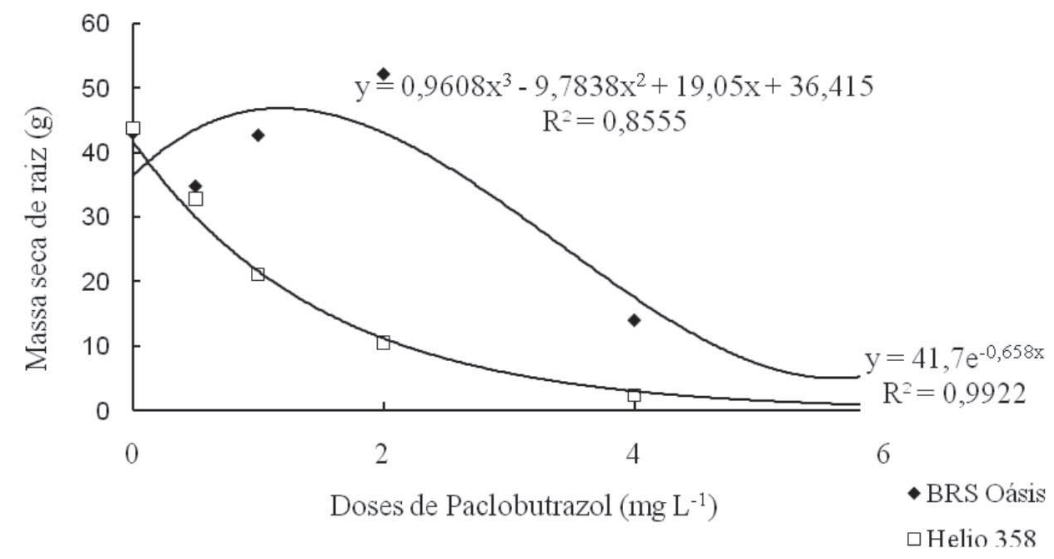

Figura 2. Massa de matéria seca de raízes de plantas dos genótipos BRS Oásis e Helio 358 em razão de doses de paclobutrazol.

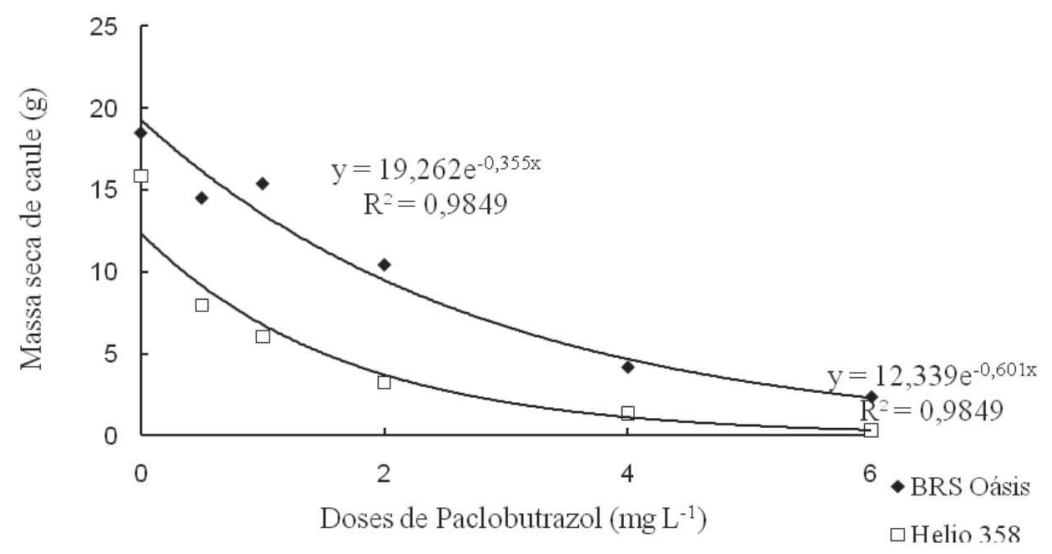

Figura 3. Massa de matéria seca de caules de plantas dos genótipos BRS Oásis e Helio 358 em razão de doses de paclobutrazol.

Rev. Ceres, Viçosa, v. 61, n.1, p. 035-041, jan/fev, 2014 
do meristema apical. Assim, a ausência aparente do efeito dos reguladores nessas características pode estar relacionada aos níveis exógenos de giberelina na planta em condições experimentais e às concentrações de reguladores utilizadas, insuficientes para promover alterações significativas nessas características.
A redução da fitomassa da matéria seca de capítulo foi relacionada com as doses de paclobutrazol, e os efeitos foram semelhantes para os dois genótipos (Figura 5). Observou-se que tanto para BRS Oásis como para Helio 358 houve redução nas massas secas dos capítulos com o aumento da dose do fitorregulador aplicado. Os valores encontrados para as fitomassas secas de Helio

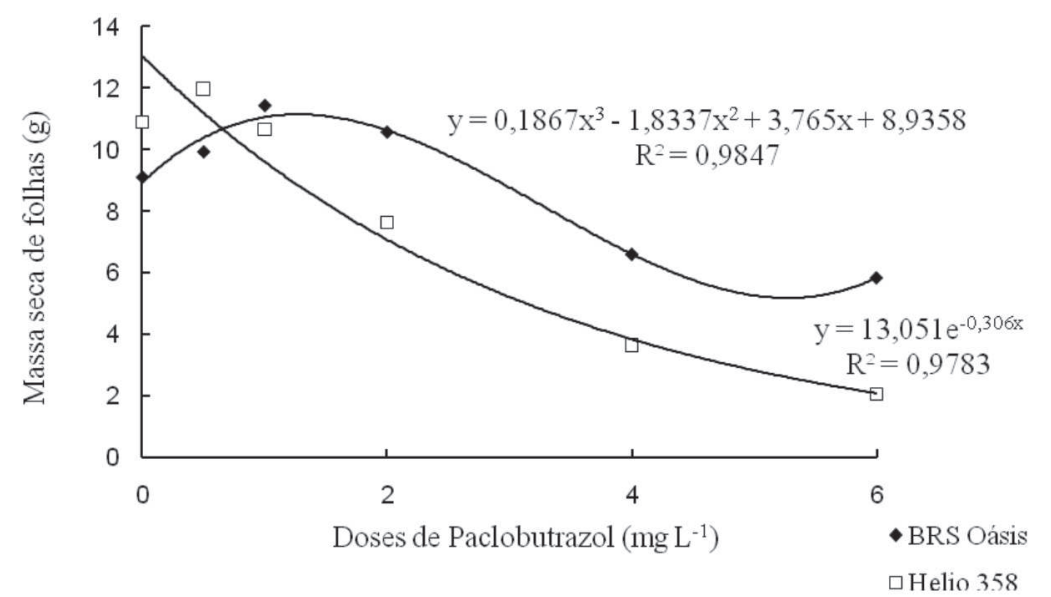

Figura 4. Massa de matéria seca de folhas de plantas dos genótipos BRS Oásis e Helio 358 em razão de doses de paclobutrazol.

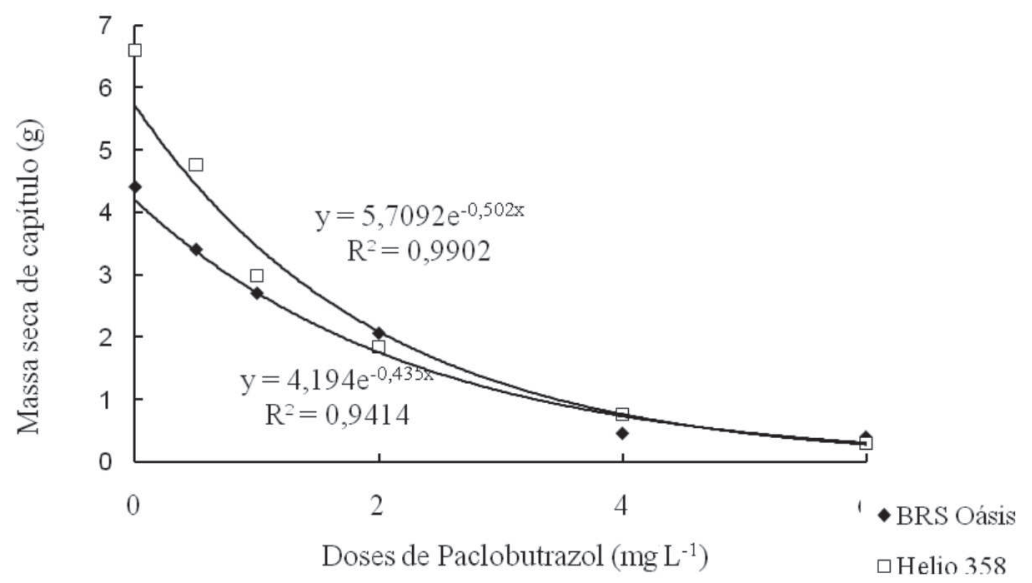

Figura 5. Massa de matéria seca de capítulos de plantas dos genótipos BRS Oásis e Helio 358 em razão de doses de paclobutrazol.

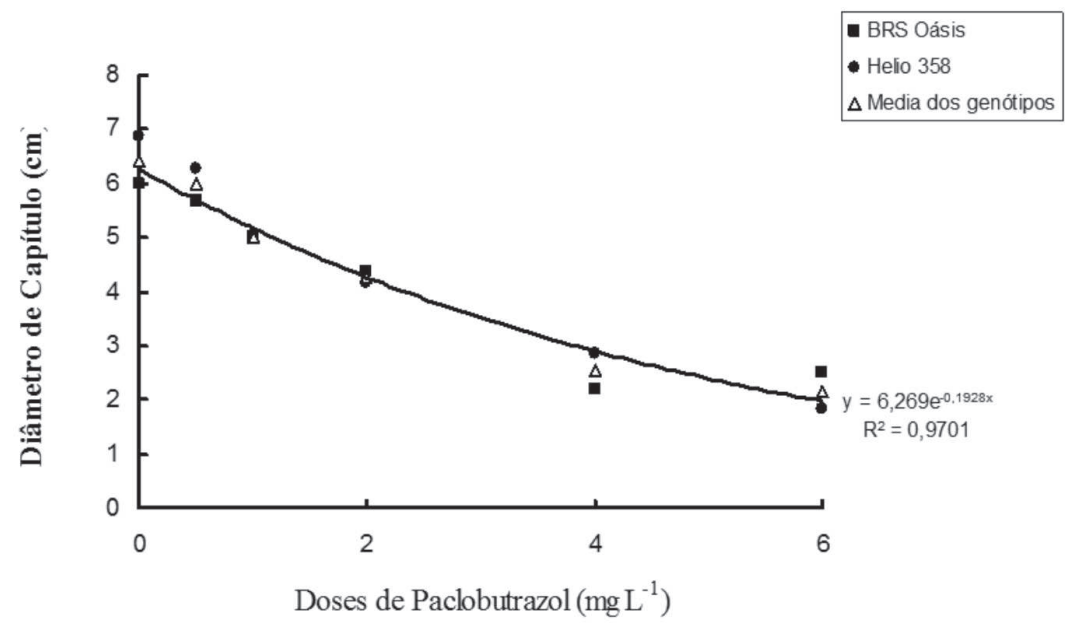

Figura 6: Diâmetro do capítulo de plantas dos genótipos BRS Oásis e Helio 358 em razão de doses de paclobutrazol. 
358 foram maiores do que os de BRS Oásis, o que poderia ser explicado pelo fato de que o híbrido Helio é uma planta para produção de grãos e deveria acumular mais nutrientes em suas sementes, e a variedade BRS Oásis foi desenvolvida para fins especificamente ornamentais e não produz sementes. Vale observar que essa diferença entre os cultivares ocorreu principalmente entre as plantas testemunhas e que essa diferença reduziu-se conforme se aumentou a dose do paclobutrazol. Resultados semelhantes foram encontrados por Valle \& Almeida (1991), que verificaram reduções de massa seca de todas

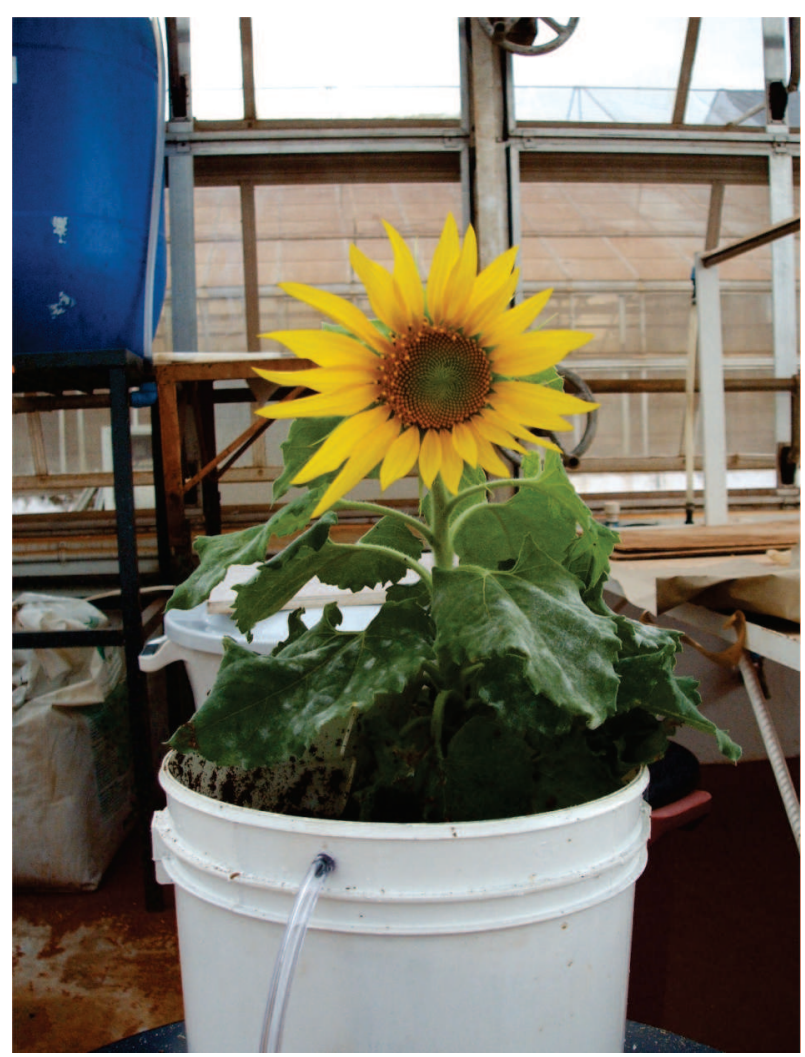

Figura 7: Planta de girassol com flor produzida na dose de $2 \mathrm{mg} \mathrm{L}^{-1}$ de paclobutrazol.

\section{CONCLUSÕES}

O uso do paclobutrazol na dose de $2 \mathrm{mg} \mathrm{L}^{-1}$ reduz a altura do girassol, porém não afeta a qualidade da inflorescência, o que pode viabilizar o seu uso na produção de flores de girassol como ornamentais. A sensibilidade ao paclobutrazol é maior para o genótipo Helio 358 em relação ao genótipo BRS Oásis.

\section{REFERÊNCIAS}

Almeida JAS de \& Pereira M de FDA (1996) Efeito de GA3 e paclobutrazol no desenvolvimento vegetativo do girassol. Revista Brasileira de Fisiologia Vegetal, 9:53-58. as partes de plantas de cacau estudadas submetidas a aplicações de paclobutrazol. Entretanto, Pinto et al. (2006) obtiveram resultados opostos, pois encontraram massa seca de inflorescências de açafrão da Cochinchina significativamente maior em plantas tratadas com paclobutrazol. Para ambos os genótipos, houve redução no diâmetro do capítulo com o aumento das doses de paclobutrazol. Esse efeito na dose de $2 \mathrm{mgL}^{-1}$ foi de $30 \%$ em relação ao controle, o que não afetou a produção e a aparência das flores produzidas, como se pode ver nas figura 6,7 e 8 .

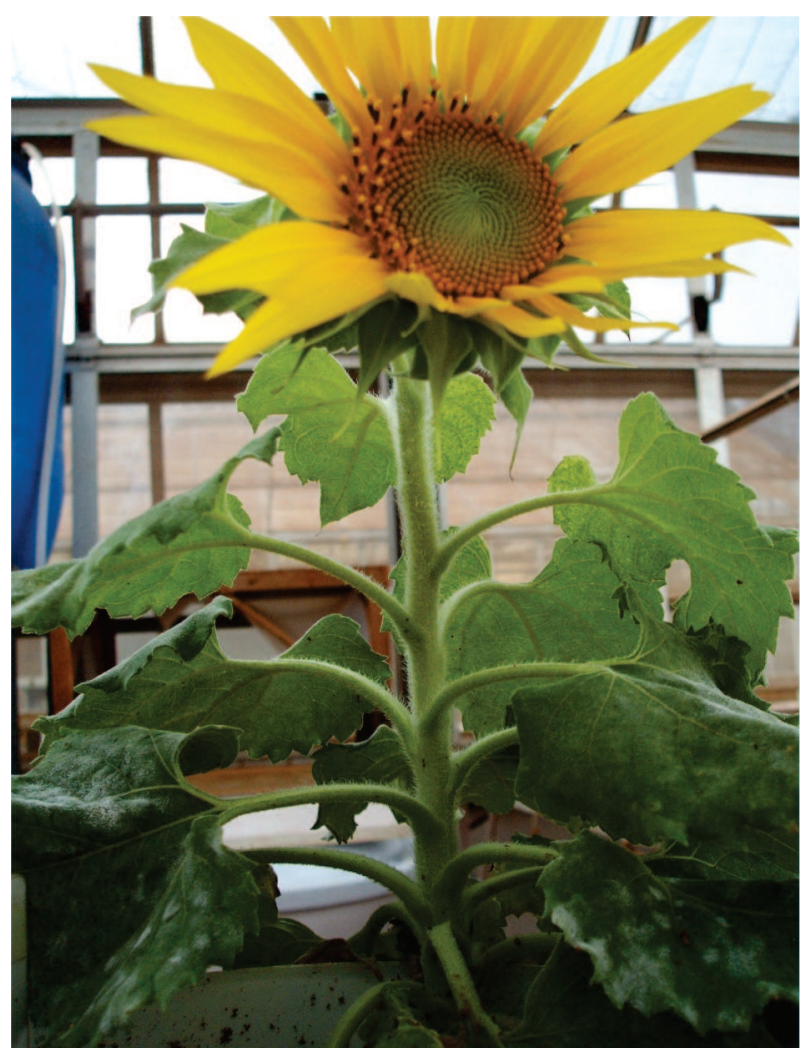

Figura 8: Planta de girassol produzida na dose de $2 \mathrm{mg} \mathrm{L}^{-1}$ de palcobutrazol. Detalhe do encurtamento dos entrenós, com produção de flor de tamanho normal.

Barbosa JG, Barbosa MS, Tsuji SS, Muniz MA, Grossi JAS \& Rubim M (2009) Cultivo de girassol ornamental (Helianthus annuus L.) em vaso sob diferentes doses de paclobutrazol. Revista Brasileira de Horticultura Ornamental, 14:205-206.

Barret J (2001) Mechanisms of action. In: Gaston ML, Konjoian PS, Kunkle LA \& Wilt MF (Eds.) Tips on regulating growth of floriculture crops. Columbus, OFA. p.32-41.

Bliska Junior A \& Honório SL (1996) Cartilha Tecnológica: Hidroponia [S.1]: n.i, 85 p.

Dasoju S, Evans MR \& Whipker BE (1998) Paclobutrazol drenches control growth of potted sunflowers. Hort Technology, 8:235237.

Epstein E \& Bloom AJ (2004) Mineral nutrition of plants: principles and perspectives. Sunderland, Sinauer Associates. 400p. 
Gianfagna TJ (1988) Natural and synthetic growth regulators and their use in horticultural and agronomic crops. In: Davies PJ (Ed.) Plant hormones and their role in plant growth and development. Dordrecht, Kluwer Academic Publishers. p.614635

Incrocci G, Mugnai S, Vernieri P, Serra G \& Tognoni F (2003) La produzione del Girasole da vaso fiorito. Colture protette, 32:105114

Embrapa - Empresa Brasileira de Pesquisa Agropecuária (2004) Informes da Avaliação de Genótipos de Girassol 2003/2004 e 2004. Londrina, Embrapa Soja. 91p. (Documentos, 250).

Joustra MK (1989) Application of growth regulators to ornamental shrubs for use as interior decoration. Acta Horticulturae, 251:359-369.

Mauk CS, Unrath CR, Bloankenship SM \& Lehman LJ (1990) Influence of method of application of paclobutrazol on soil residues and growth retardation in a "Starkrinson -Delicious" apple orchand. Plant Growth Regulation, 9:27-35.

Pallez LC, Dole JM \& Whipker BE (2002) Production and post production studies with potted sunflowers. Hort Technology, 12:206-210.

Pateli P, Papafotiou M \& Chronopoulos J (2004) Comparative effects of four plant growth retardants on growth of Epidendrum radicans. Journal Horticulturae Science Biotechnology, 79:303307

Pinto ACR, Graziano TT, Barbosa JC \& Lasmar FB (2006) Retardadores de crescimento na produção de plantas floridas envasadas de açafrão da Cochinchina. Bragantia, 65:369-380.

Reyes FGR, Garibay CB, Ungaro MRG \& Toledo MCF (1985) Girassol: cultura e aspectos químicos, nutricionais e tecnológicos. Campinas, Fundação Cargill. 86p.
Ribeiro MCC, Gurgel Junior CA, Mendes VH de C, Benedito CP, Oliveira GL, Nunes TA \& Figueiredo M de L (2007) Utilização do retardante de crescimento paclobutrazol em Girassol (Helianthus annuus). Revista Brasileira de Biociências, 5:11041106.

SAS Institue Inc. (1994) SAS/STAT Software: Changes and Enhancements, Release 6.10. Cary, Statistical Analysis System Institute.

Stefanini MB, Rodrigues SD \& Ming LC (2002) Ação de fitorreguladores no crescimento da erva cidreira brasileira. Horticultura Brasileira, 20:18-23.

Valle RR \& Almeida AAF de (1991) Efeitos retardantes do paclobutrazol aplicado em diferentes estágios de crescimento de plântulas de cacau. Pesquisa Agropecuária Brasileira, 26:19111917.

Vernieri P, Incrocci G, Tognoni F \& Serra G (2003) Effect of cultivar, timing, growth retardants, potting type on potted sunflowers production. Acta Horticulturae 614:313-318.

Wanderley CS da, Rezende R \& Andrade CAB de (2007) Efeito do Paclobutrazol como regulador de crescimento e produção de flores de girassol em cultivo hidropônico. Ciência e Agrotecnologia, 31:1672-1678.

Whipker BE \& MCCall I (2000) Response of potted sunflower cultivar to daminozide foliar sprays and paclobutrazol drenches. Hort Technology, 10:209-211.

Wilkinson RI \& Richards D (1987) Effects of paclobutrazol on growth and flowering of Bouvardia humboldtii. Hort Science, 22:444-445. 